\title{
Application of the MIPS method for assessing the sustainability of production-consumption systems of food
}

Originally published as:

Lucia Mancini, Michael Lettenmeier, Holger Rohn, Christa Liedtke (2012):

Application of the MIPS method for assessing the sustainability of productionconsumption systems of food

In: Journal of economic behavior and organization, 81, 3, 779-793 


\section{Application of the MIPS method for assessing the sustainability of production-consumption systems of food}

*Corresponding author: Lucia Mancini, Università Politecnica delle Marche, SAIFET Department luciamancini25@gmail.com

a Università Politecnica delle Marche, SAIFET Department (Ancona, Italy)

b Wuppertal Institute for Climate, Environment and Energy

Keywords: sustainability, value chain, natural resource, food, agriculture, MIPS

JEL codes: Q57, Q56, Q10

\section{Short abstract}

The article estimates the natural resource consumption due to nutrition from the supply and demand sides. Using the MIPS (Material Input per Service Unit) methodology, we analyzed the use of natural resources along the supply chains of three Italian foodstuffs: wheat, rice and orange-based products. These figures were then applied for evaluating the sustainability of diets in 13 European countries. The results outline which phases in food production are more critical in terms of natural resource consumption. We also observed different levels of sustainability in the European diets and the effect of different foodstuffs in the materials, water and air consumption. 


\section{Introduction}

The ongoing increase of the world population calls the agro-food systems of all countries for huge challenges. Agriculture has to satisfy growing food requirements both in quantitative and qualitative terms, but the on hand natural resource stock is quickly depleting. Moreover, food production and energy production from biomass are competing for land (Pimentel 2008, Hahlbrock 2009).

"Nutrition" is one of the most material demanding areas of need, accounting approximately $20 \%$ of the total natural resource consumption of German economy (Rithoff et al. 2009). It stands to reason that food-farming systems sustainability has a crucial importance in the world economy.

Different assessment tools for evaluating the impact of food in the ecosystems can be used, e.g. Life Cycle Analysis, energy requirements indicators, virtual water and carbon footprint of food (Kramer et al. 1999; De Fraiture et al. 2001). Nevertheless, a comprehensive ecological indicator should cover main environmental categories, consider the life cycle wide of a product or service and be understandable and easy to communicate to a non-expert audience (Burger et al., 2009).

In this context, we propose a material input based methodology (MIPS, the Material Input Per unit of Service) for assessing the environmental sustainability of food production and consumption. According to this approach, the volume of primary materials that are extracted from nature for the economic activities indicates a generic pressure on environment. Targeted to a product or a service, MIPS gives a preliminary estimation of the potential environmental impact of those products or services and allows comparing alternatives that provide the same service.

The analysis regards both the supply and demand side of food sector. In the first part, we calculated MIPS for Italian foodstuffs (wheat, rice and orange- based products) along their supply chains. LCA data and information from the literature were the main sources of data. We could outline which factors and phases are more relevant in the supply chains for a reduction of the material input. In the second part, we used MIPS results on Italian productions and other figures from the literature for accounting the natural resource consumption due to nutrition in 13 European countries and in EU. A set of MIPS-based indicators was calculated for outlining the intensity in the use of three resources: materials, water and air. The interpretation of results allowed highlighting the sustainability of different diets. We also detected which foods in diets are affecting more sustainability and commented these outcomes with the ones from another application of MIPS in food consumption.

\section{Methodology}

\subsection{MIPS concept}

MIPS stands for Material Input per Service Unit and estimates the environmental 
pressure caused by products or services. The equation

$$
\text { MIPS }=\frac{M I}{S}
$$

shows that MIPS is the reciprocal of resource productivity. Thus, this indicator tells us how much "nature" we are using for producing or consuming something. Material Input (MI) encompasses all matter and energy flows from natural systems to techo-sphere, in mass units. Energy is included through the energy carriers quantification in terms of mass. They also include the "ecological rucksacks", i.e. "the total mass of material flows that are not physically included in the economic output under consideration but have been necessary for production, use, recycling and disposal" (Spangenberg, 1999). Backward chains of a specific product have to be also accounted for a proper estimation of ecological rucksacks.

Five or six different categories of material inputs are considered: abiotic (nonrenewable resources like mineral row materials, fossil energy carriers, soil excavations), biotic (renewable resources from agriculture and silviculture) earth movement in agriculture and silviculture (mechanical earth movement), water (surface, ground and deep ground water) and air (all parts of the air that are changed chemically, i.e. mainly the quantity of oxygen combusted that reflect the amount of carbon dioxide formed); also erosion can be calculated separately.

The "Service Unit" component ( $S$ in equation 1 ) refers to the benefit that is provided using material or immaterial goods. The dimension unit of this part depends on the object under consideration and the specific performance it provides (e.g. person- kilometers for a mean of transport, floor area for buildings). Products that are used just once (for instance, food) have $\mathrm{S}=1$ and

$$
M I=E R+P W
$$

where ER is the ecological rucksack and PW is the weight of the product we are considering.

Relating the material input with the service unit allows comparing different ways for fulfilling a need, or alternative productive techniques for producing something, on the base of their intensity in resource use. Thus, MIPS can be also defined as the "ecological price of a utility" (Schmidt-Bleek, 2008) and be easily integrated in the economic analysis.

In order to avoid the calculation out of primary data each time, MIPS calculation is often done using average MI factors for materials and other inputs. They are the ratio between the quantity (in mass units) of resources used and the quantity (mass) of product obtained. Many MI factors of materials and "modules" (electricity, transport, etc.) have been calculated and are published by Wuppertal Institute (available online: http://www.wupperinst.org/uploads/tx_wibeitrag/MIT_v2.pdf). The use of readycalculated MI factor makes MIPS calculation easier, because not every pre-processchain needs to be recalculated by each user.

The theoretical basis of MIPS lays in Material Flow Analysis (MFA). The common 
consideration is that productive processes are extracting resources from nature and transforming them in something suitable (the product) and something unsuitable (emissions, waste, etc.). The quantification of the throughput of process chains and the minimization of these physical exchanges between human society and environment is the aim of MFA (Bringezu et al., 2002).

MIPS has an input-oriented approach. Consistently with the matter-energy conservation law it assumes that, as the input and the output side are equivalent in quantitative terms, accounting the input side is enough to have a preliminary estimation of the environmental impact of products and services (Ritthoff et al. 2002; Schmidt-Bleek, 1993).

The input-orientated approach of MIPS also implies that MIPS is not a sufficient indicator when measuring specific outputs (e.g. emissions of specific substances) or specific environmental impacts (like acidification or toxicity). Thus, MIPS allows conclusions on the overall pressure on the environment (as any input into the human production-consumption system will become an output at some point in time) but not on specific environmental impacts. As MIPS contains all physical input flows, it is rarely used in index-type combination with output indicators, because this would affect double-counting certain material flows.

On a microeconomic level, MIPS can be applied in a variety of products and services for evaluating eco-innovations and identifying eco-efficiency improvements along the supply chains (Burger et al, 2009). It is also applicable at a macroeconomic level for an evaluation of the sustainability of the economic growth in national and regional economies. It has also been used for an evaluation of policies from the environmental point of view (Lettenmeier et al. 2008). The most controversially discussed aspect of the MIPS concept is probably the link between the mass flow of resources and the environmental impacts caused by it. The traditional approach of environmental policy focused rather on the impact of hazardous substances in the output flows than on the material flow input, considering also the possibility of material recycling and the treatment of waste and emissions. Nevertheless, the importance of input mass flows and the necessity of a reduction of these amounts are evident. The both economic and ecological costs as well as the incompleteness of output treatments and the impossibility of a complete recycling of materials are some common reasons for this approach (Lettenmeier et al. 2006). Moreover, the specific environmental impact of most substances humans release to nature is even partly known only for a very limited amount of substances. Thus, the amount of materials moved from their original location can be considered a proxi measure for the human use of natural capital potential environmental impact (Hinterberger et al., 1997).

\subsection{MI-based indicators for sustainability strategies}

A drastic reduction in material resources use is necessary for approaching sustainability. Accounting the material input of products and economies is essential to enforce a dematerialization strategy both at micro and macro level. Depending on the objects of evaluation, different indicators based on the material 
requirements can be used. For the interpretation of MIPS results, the different resource categories have to be examined separately. So far, the "earth movement in agriculture and silviculture" category is often left out from the interpretation as the available documentation is still inadequate and just "erosion", which is encompassed in this category, is considered. In this study, we neglected the interpretation of soil movements but considered erosion inside TMR (Total Material Requirement):

$$
M I[T M R]=M I[\text { abiotic }]+M I[\text { biotic }]+M I[\text { erosion }]
$$

This indicator gives instantaneous information about the use of materials of different alternatives (Rithoff et al., 2002).

In order to implement dematerialization strategies resource productivity has to be stressed. At the same time requirements of resources should decrease also in absolute terms. Technologies and innovations can be evaluated measuring MIPS along the various steps of the value chain and in the different category of resources (Lettenmeier et al., 2009). At least three equations should be minimized:

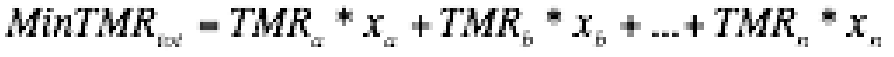

$$
\begin{aligned}
& M i n M I w_{b t}-M I w_{s} * x_{s}+M I w_{b} * x_{b}+\ldots+M I w_{n}^{*} x_{n} \\
& \operatorname{MinMIa}_{\mathrm{ax}}=\mathrm{MIa}_{z} * x_{u}+\operatorname{MIa}_{b} * x_{b}+\ldots+\operatorname{MIa}_{n} * x_{n}
\end{aligned}
$$

where: TMR, MIw and MIa are the requirements of material resources, water and air in all the phases of value chain; a, b, c, n represent the various steps of the value chain, from the extraction of raw materials up to the consumption phase; $x_{n}$ are the amounts of good that is produced or consumed in each phase.

TMR is also used in resource accounting of national economies (United Nations et al., 2003, Bringezu et al. 2001). In this case it refers to the total mass of natural material resources used in the economy and it is calculated as:

$$
T M R=D M I+D H F+i D M I+i H F
$$

where: DMI is the Domestic direct Material Input i.e. the flows of domestic natural resource commodities entering the economy; DHF is the Domestic Hidden Flows i.e. the unused extractions linked to DMI (e.g. excavated and disturbed materials and biomass that is removed but not used for production); iDMI is the imported Direct Material Input, that is all the flows of resources coming from abroad; iHF is the Hidden Flows associated with imports (in the literature DMI often stands for Direct Material Input, that is the sum of domestic and imported flows used in the national economies). TMR of European Union has been calculated by the European Environment Agency (EEA, 2001) and many MFA of national economies are already available in the literature. Information on material flows can be used for adjusting GDP with the depreciation of natural capital due to economic activity and evaluate the sustainability of economic growth (Hinterberger et al., 1997). 


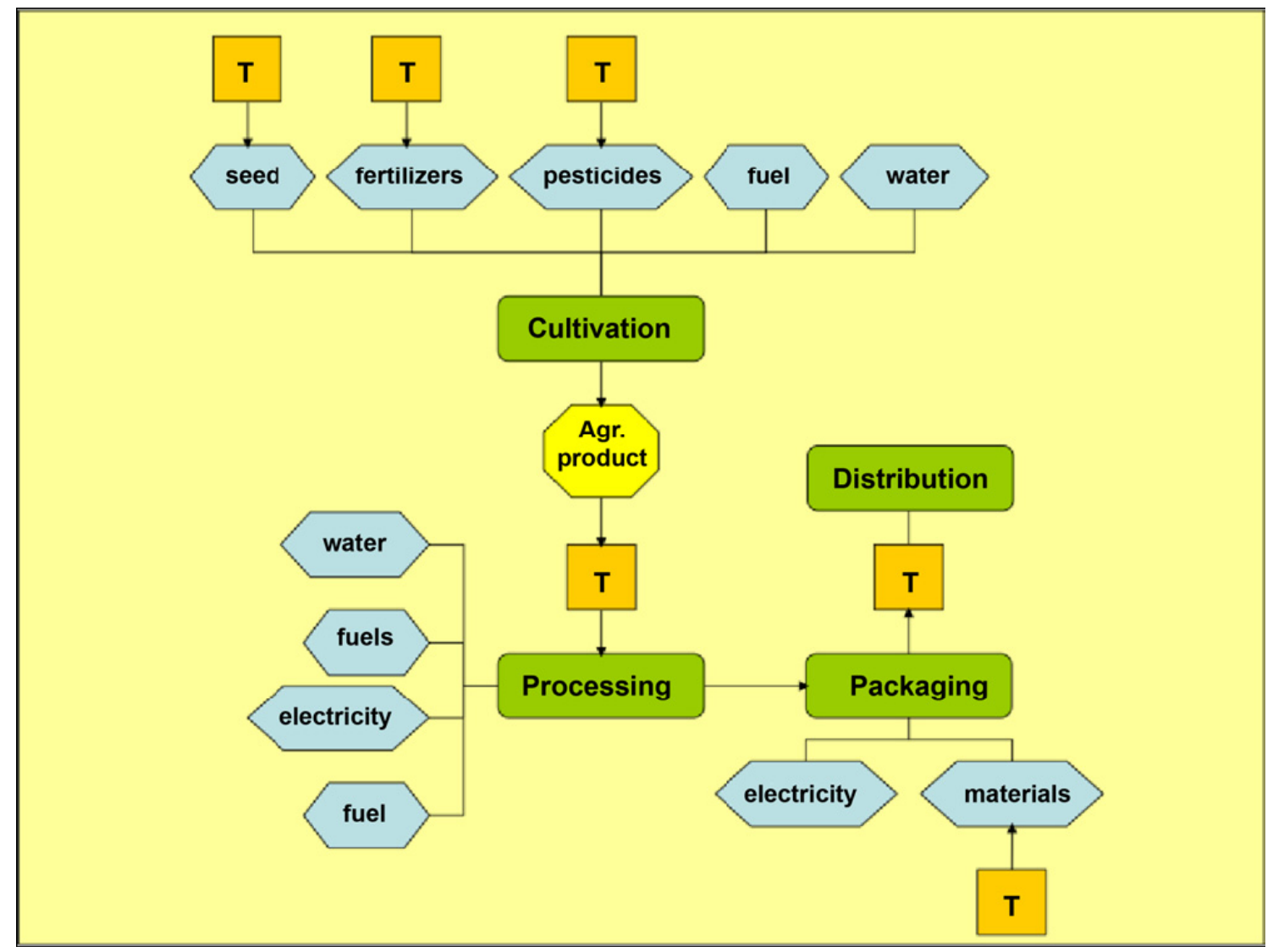

Figure 1. System boundaries for MIPS calculation of foodstuffs. "T" stands for transport process

Pursuing the eco-efficiency of consumption behaviors and production processes has a positive feedback also in economic terms because it allows gaining a better resource allocation. On the production side, eco-efficiency entails a cost reduction, since the resources are managed in a more rational way. Moreover, acting upstream through a minimization of resource use, the downstream costs for waste management, pollution treatment and purification are also reduced. Nevertheless, the ecological and economic efficiency can diverge when market prices underestimate the biophysical scarcity of natural resources and overestimate the capacity of the ecosystems as a sink, thus encouraging a wasteful management. Therefore, an integrated evaluation of economic and ecological efficiency of processes can be useful for providing information on the overall performance of processes. Using DEA (Data Envelopment Analysis) models Kauppinen et al. (2008) studied the sustainability of food consumptions, scoring a set of foodstuffs on the basis of the overall (economic and ecological) efficiency. In this study,

the material intensity of foodstuffs and their prices are considered as inputs in the DEA model, while the food's nutritional values are used as output. The results show the efficiency of each foodstuff in providing individuals with a proper amount of nutrients while minimizing the material input and the household expenditure. A similar investigation can be applied on the supply hand for evaluating the overall efficiency of productive processes. 


\subsection{Material intensity analysis of food value chains}

In the first part of the study we used the MIPS approach for investigating the ecological rucksacks of three Italian foodstuffs along their supply chains: wheat, rice (milled and parboiled rice from conventional farming and milled rice from organic farming), and citrus-based products (oranges, natural and concentrated orange juice). The scope of the study was two-fold. From the supply side, we wanted to test the MIPS methodology as a tool for sustainable food production; from the demand side, we wanted to use these estimations for the assessment of natural resource consumption due to nutrition in different European areas.

The first step of the supply chain analysis was to assess the material intensity of some Italian foodstuff and agricultural products. The choice of products was based on their representativeness of Italian agro-food sector and their importance in diet. We also considered the availability of data and life cycle assessment surveys, which are the main sources of information for material intensity accounting. Statistics and other surveys from the literature have been also used for completing the data basis.

Soil erosion statistics are not available for different crops in Italy. We applied to the three crops (wheat, rice and orange grove) the estimation of $10 \mathrm{t} / \mathrm{ha}$ year of erosion in Italian agriculture use published by national statistical agency in 2003 (Istat, 2003). The system boundaries were defined from the production and transportation of the chemicals and other inputs for agriculture (Fig.1) up to the distribution to the selling points. The transport of the packaging materials and the means of transports are also included, while the impact of infrastructures and the capital goods is neglected.

We choose the service unit of $1 \mathrm{~kg}$ of food, without considering the content of different nutrients provided by the foodstuff.

Thus, the results are expressed as $\mathrm{kg}$ of materials per $\mathrm{kg}$ of food. The MIPS indicator can focus both on micro-economic level (taking data from a single enterprise) and on macro-economic level, using average data from different sources or national statistics (Baedeker et al., 2008). Depending on the availability of data, we used the first or the second approach with a focus on micro level data in production and on macro level in consumption. The MIPS-based indicator, TMR (for details, see above), includes the abiotic, biotic and erosion categories and was used for an interpretation of the results. Material intensities of fertilizers, pesticides, fuels, means of transport and all the materials and energy carriers used in agriculture and food industry are from the available literature (www.mipsonline.info). They are not specific for Italy but most of them have been calculated for Germany or Europe. The material intensity of electricity is available for European and OECD countries and has been applied in the calculation.

For the MIPS calculation of wheat we used average data from three different LCA surveys (Bevilacqua et al., 2001, 2007; Della Corte et al., 2003) that investigate the production of two different brands of pasta. We considered only conventional durum wheat cultivation, with nitrogenous and phosphorous fertilization and pest 
treatments. Irrigation is usually not necessary for durum wheat cultivation, except in case of extraordinary drought. Therefore, we excluded it from the MIPS calculation. The average yield from the literature is $5678 \mathrm{~kg} / \mathrm{ha}$; for the accounting of earth movements in agriculture we assumed a maximum depth of ploughing of $30 \mathrm{~cm}$ and an average soil density of $1300 \mathrm{~kg} / \mathrm{m} 3$.

The system includes the transports of raw materials and inputs and the trip to the milling point. Information about rice from conventional agriculture (milled and parboiled) is from Blengini and Busto (2008). These average data are representative of a typical farm in the Vercelli district in the North-West of Italy (this area provides 33 percent of national rice production). We considered an average yield of $7040 \mathrm{~kg} / \mathrm{ha}$ of paddy rice, with the resort of nitrogenous, phosphorous and potassic fertilization and pest treatments. Earth movements include tilling, ploughing and the maintenance of water canals; irrigation is based on the network of canals where water flows without the use of any pumping systems. The annual water consumption for irrigation is $19,800 \mathrm{~m} 3 / \mathrm{ha}$. Fuel consumption for field operation is from ENAMA (National Agency for Agriculture Mechanization) and Ministry for Agriculture statistics.

All the transports are included in the system. We assumed a local distribution to the retailers with an average distance of $200 \mathrm{~km}$. Parboiled rice needs a special treatment after the drying of paddy rice. It consists of boiling, soaking, steaming and drying again. The packaging of milled and parboiled rice is made of a polyethylene bag and an external carton box. Data on organic rice (Mandelli et al., 2005) refer to a specific farm, in the area of Milan. The breeding activity of the same farm provides manure and slurry for the fertilization; mustard seeds are sowed before rice for improving the chemical characteristics of the soil. The yield of paddy rice is $5000 \mathrm{~kg} / \mathrm{ha}$ and the water for irrigation is $2500 \mathrm{~m} 3 / \mathrm{ha}$, according to Mandelli. The organic rice is packed in a cotton bag and an internal polyethylene film.

We applied the MIPS methodology to the production of oranges, natural (NJ) and concentrated (CJ) orange juice, based on Beccali et al. (2009) LCA information. The area of cultivation is Sicily and the manufacturing process of citrus-derived products regards a Sicilian factory with regional representative size.

In the conventional farming of citrus groves nitrogenous, phosphorous and potassic nutrients are applied and water consumption for irrigation is about 4200 $\mathrm{t} / \mathrm{ha}$. We assumed the deepest ploughing being $80 \mathrm{~cm}$ before the planting, one time in 25 years (the life span of the grove) and a soil density of $1350 \mathrm{~kg} / \mathrm{m} 3 . \mathrm{We}$ neglected the nursery production. The average yield is $25 \mathrm{t} / \mathrm{ha}$ of oranges. The manufacturing process of $\mathrm{NJ}$ is composed of selection and washing, primary extraction, refining, pasteurization and cooling, refrigeration and packaging. CJ needs an additional treatment for reducing the amount of water. One kilogram of oranges provides $0.142 \mathrm{~kg}$ of NJ and $0.028 \mathrm{~kg}$ of CJ.

We assumed average transport distances of $150 \mathrm{~km}$ from the field to processing and $500 \mathrm{~km}$ from processing to retailers. The products are packed into LDPE bags. 


\subsection{Material intensity of European diets}

MIPS results on foodstuffs were applied for assessing the natural resource consumption due to nutrition in European countries. We took into account the consumption of 18 foodstuffs in 13 European countries and in the European Union. The main source of data was the Eurostat report "From farm to fork"(EUROSTAT2008). It provided figures on gross human apparent consumption of foodstuffs per capita of the twenty-seven European Union's countries. We excluded from the analysis all the countries with lacking data for food consumption in 2007 and took only the foodstuffs for which material intensity 1 were available in the literature (we excluded from 27-EU: Malta, Denmark, Estonia, Lithuania, Latvia, Bulgaria, Czech Republic, Hungary, Romania, Slovakia, Slovenia, Belgium and Luxemburg).

Previous results on material intensities of wheat, rice and oranges were used for this application. The other figures are from German (Ritthoff et al. 2009) and Finnish (Kauppinen et al. 2008) studies on agriculture and nutrition. Some values have been estimated by the authors on the base of similar food categories already existent. The Material intensity of pears, for instance, was assumed to be like the one of apples; we used fresh tomatoes figures also for processed tomatoes and the cattle figures also for sheep and goats. In table 1 is a list of material intensities and the information sources. The same material intensities were used for every country, as no specific data was available. This means that the wide variability of environmental and climatic conditions as well as specific agronomic techniques and processes could not be taken into account. Moreover, neither the cooking, preparation of the food at home, nor the question if they are domestically produced or imported were included in the analysis. However, the same methodology proposed here can be used with specific data once they will be available in order to have a more accurate assessment.

\footnotetext{
${ }^{1}$ In the case of food, MIPS values are also called we Material Intensity because the service has the same unit measurement then the MI $(\mathrm{kg} / \mathrm{kg})$.
} 
Table 1. Material intensities of foodstuffs

\begin{tabular}{|lcccccc|}
\hline \multicolumn{1}{|c}{ Foodstuffs } & ABIOTIC & BIOTIC & WATER & AIR & SOIL & EROSION \\
\hline Wheat (c) & 0.34 & 2.13 & 30.84 & 0.29 & 731.9 & 1.87 \\
\hline Rice (c) & 2.53 & 3.84 & 4804 & 0.94 & 2589 & 2.40 \\
\hline Potatoes (a) & 0.10 & 1.06 & 0.4 & 0.01 & 113 & 0.22 \\
\hline $\begin{array}{l}\text { Vegetable oils \& } \\
\text { fats (a) }\end{array}$ & 4.50 & 3.72 & 70.5 & 0.98 & 5490 & 11.49 \\
\hline Sugar (a) & 8.58 & 12.6 & 53.7 & 4.70 & 542 & 1.15 \\
\hline Apples (b) & 1.00 & 1.00 & 7.0 & 0.01 & 93 & 0.32 \\
\hline Oranges (c) & 0.20 & 1.00 & 181 & 0.11 & 17 & 0.40 \\
\hline Pears (b) & 1.00 & 1.00 & 7.00 & 0.01 & 93 & 0.32 \\
\hline Tomatoes (b) & 8.00 & 1.00 & 793 & 4.00 & 36 & 0.01 \\
\hline Cattle (a) & 10.9 & 26.4 & 451 & 2.81 & 3329 & 11.1 \\
\hline Poultry (a) & 6.44 & 5.93 & 234.9 & 1.63 & 3405 & 5.90 \\
\hline Pigs (a) & 2.57 & 6.89 & 62.3 & 1.01 & 2968 & 6.51 \\
\hline $\begin{array}{l}\text { Sheeps and goats } \\
\text { (a) }\end{array}$ & 10.86 & 26.39 & 450.8 & 2.81 & 3329 & 11.12 \\
\hline Fish \& seefood (a) & 2.80 & 4.70 & 271.0 & 0.83 & 148 & 0.17 \\
\hline Drinking milk (a) & 0.15 & 2.75 & 4.7 & 0.03 & 259 & 0.89 \\
\hline Butter (a) & 3.42 & 56.87 & 105.8 & 0.79 & 5366 & 18.43 \\
\hline Cheese (a) & 0.84 & 14.24 & 25.5 & 0.20 & 1344 & 4.62 \\
\hline Eggs (a) & 1.15 & 1.98 & 28.56 & 0.25 & 605.9 & 0.93 \\
\hline
\end{tabular}
(a) Ritthoff et al. 2009
(b) Kauppinen et al. 2008
(c) Our MIPS results for Italian productions

Using this set of data, we calculated the following indicators:

(8)

$$
\begin{gathered}
R I T_{i, j, k}-M I_{i, j, k} * X_{i, j} \\
T M R_{i, j}=\operatorname{MIT}(a b)_{i, j}+M I T(b)_{i, j}+M I T(e r)_{i, j} \\
W R_{i, j} \\
A R_{i, j} \\
T M R_{j}-\sum_{j=1}^{15} T M R_{i, j} \\
T W R_{j}-\sum_{j=1}^{15} W R_{i, j} \\
T A R_{j}-\sum_{i=1}^{18} A R_{i, j} \\
A M I_{j}-\frac{T M R_{j}}{X_{j}}
\end{gathered}
$$




$$
\begin{aligned}
& A W I_{j}=\frac{M T T(w)_{j}}{X_{j}} \\
& A A I_{j}=\frac{M T T(a)_{j}}{X_{j}}
\end{aligned}
$$

where:

$i-[1 \ldots 18]$ is the foodstuff; $j-[1 \ldots 14]$ is the country (EU included); $k-[1 \ldots 6]$ is the resource category; $\mathrm{X}_{\mathrm{i}, \mathrm{j}}$ are the amounts of the foodstuff $\mathrm{i}$ consumed in the country $\mathrm{j}$; $\mathrm{RIT}_{\mathrm{i}, \mathrm{j}, \mathrm{k}}$ (Resource Intensity) represents the amount of the resource $\mathrm{k}$ that is on average necessary for the consumption of foodstuff $i$ by a inhabitant of the country $\mathrm{j}$; $\mathrm{TMR}_{\mathrm{i}, \mathrm{j}}$ is the total material requirement for the consumption of foodstuff $\mathrm{i}$ in the country $\mathrm{j} ; \mathrm{WR}_{\mathrm{i}, \mathrm{j}}$ and $\mathrm{AR}_{\mathrm{i}, \mathrm{j}}$ are the requirements of water and air for the consumption of foodstuff $i$ in the country $j$; $\mathrm{TMR}_{\mathrm{j}}$ is the total material requirement for food (that is the set of 18 foodstuffs) of the country $\mathrm{j}$; $\mathrm{TWR}_{\mathrm{j}}$ and $\mathrm{TAR}_{\mathrm{j}}$ are the total requirements for water and air for food (that is the set of 18 foodstuffs) of the country $\mathrm{j} ; \mathrm{AMI}_{\mathrm{j}}, \mathrm{AWI}_{\mathrm{j}}, \mathrm{AAI}_{\mathrm{j}}$ are the average resources intensity (for materials, water and air), i.e. the average amount of resource that is used for consuming one unit of food in a given country.

The comparison of the resource intensities (materials, water and air) of diets facilitates a rough assessment of their sustainability. In addition, we can outline how different groups of food are contributing to the natural resource consumption of nutrition. Countries were graded on the base of total annual consumption and TMR of the selected foodstuffs per capita, and the average intensity of materials, of water and of air.

\section{Presentation and description of results}

\subsection{MAIA analysis of the supply chains}

\subsubsection{Results for wheat}

Table 1 presents the material intensity results of durum wheat; fig. 2 shows the contribution of different phases of the supply chain. The TMR for one kilogram of durum wheat is $4.35 \mathrm{~kg}$. Fig. 2 shows the contribution of different input factors in the total resource use due to wheat cultivation. $84 \%$ of water consumption is due to pesticides production, while two-thirds of total abiotic materials are used for producing chemical products for agriculture (that include fertilizers and pesticides). Fuel for field operation weigh $40 \%$ of the total air consumption, while transport operations from storage to milling place consume $13 \%$ of air and $12 \%$ of abiotic materials.

Table 2. Material intensity of conventional durum wheat

\begin{tabular}{|l|c|c|c|c|c|c|c|}
\hline & ABIOTIC & BIOTIC & EROSION & SOIL & WATER & AIR & TMR \\
\hline $\begin{array}{l}\text { Material } \\
\begin{array}{l}\text { Intensity } \\
\text { (kg/kg) }\end{array}\end{array}$ & 0.34 & 2.13 & 1.87 & 731.9 & 30.84 & 0.29 & 4.34 \\
\hline
\end{tabular}




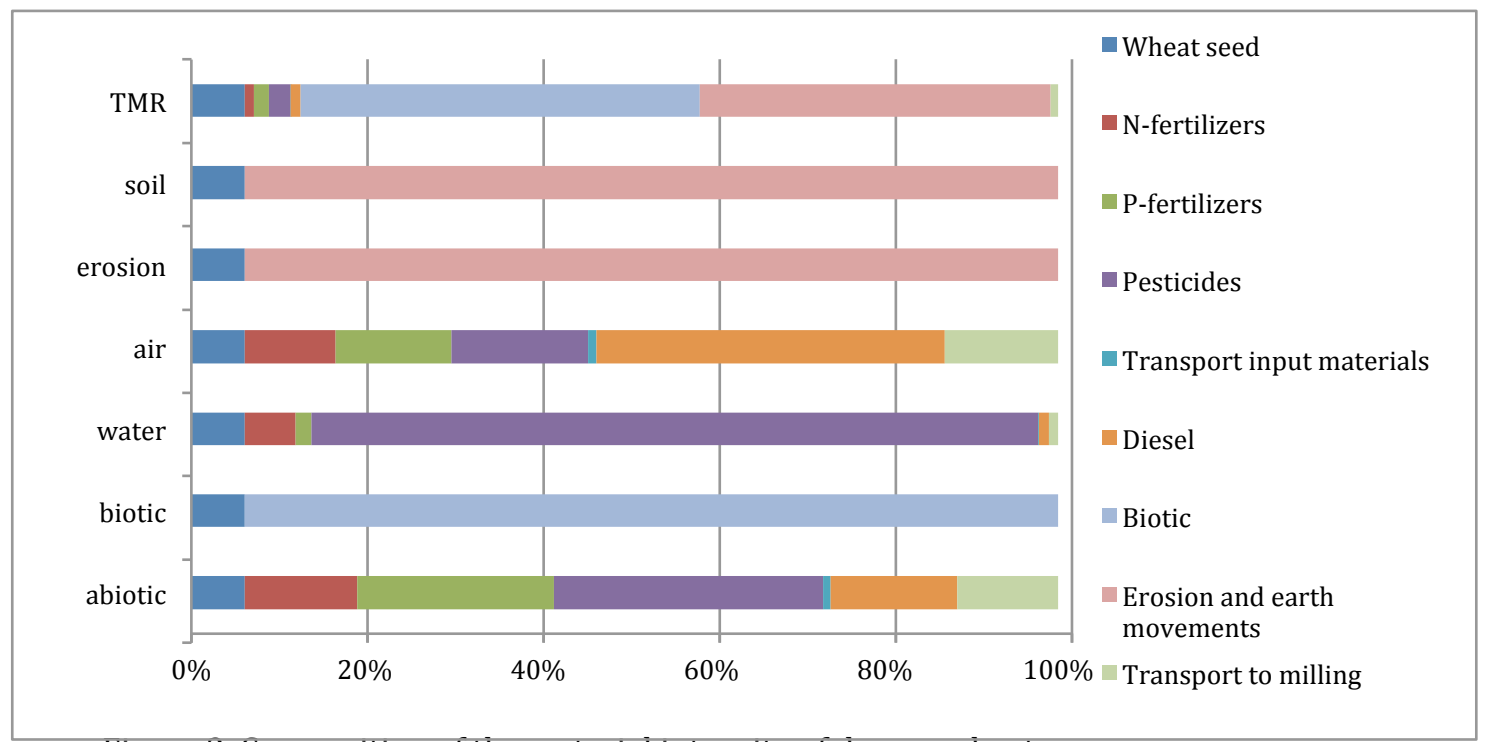

Figure 2. Composition of the material intensity of durum wheat

\subsubsection{Results for rice}

TMRs of rice are $8.91 \mathrm{~kg} / \mathrm{kg}$ for milled one, $9.43 \mathrm{~kg} / \mathrm{kg}$ for parboiled and 9.04 $\mathrm{kg} / \mathrm{kg}$ for organic one (table 3). For the three kinds of rice, more than $70 \%$ of TMR is due to farming (Fig. 3,4 and 5). In conventional rice (milled and parboiled) the impact of fertilizers is relevant for the category of abiotic resources $(40 \%$ and $34 \%$ ) and irrigation is responsible for almost the total consumption of water. Transports are also quite important for the consumption of air $(28 \%$ and $21 \%$ of the total). Electricity affects more parboiled rice, which has higher material intensities also in absolute terms (in the categories of abiotic, air and water). Concerning the organic rice, the TMR is not lower than the conventional ones (8.93 $\mathrm{kg} / \mathrm{kg}$ ). In opposite to a minor consumption of abiotic resources, in which packaging materials and electricity are contributing more, biotic resources and erosion contributes to a higher TMR. Air and water consumption are lower in organic rice and affected more by packaging materials than transport and electricity.

Table 3. Material intensity of rice

\begin{tabular}{|l|c|c|c|c|c|c|c|}
\hline $\begin{array}{l}\text { Material Intensity } \\
(\mathrm{kg} / \mathrm{kg})\end{array}$ & ABIOTIC & BIOTIC & EROSION & SOIL & WATER & AIR & TMR \\
\hline $\begin{array}{l}\text { Milled } \\
\text { conventional rice }\end{array}$ & 2.53 & 3.84 & 2.40 & 2589 & 4804 & 0.94 & 8.77 \\
\hline $\begin{array}{l}\text { Parboiled } \\
\text { conventional rice }\end{array}$ & 3.20 & 3.84 & 2.40 & 2589 & 4828 & 1.37 & 9.43 \\
\hline Organic milled & 1.14 & 4.16 & 3.57 & 3866 & 1457 & 0.43 & 8.89 \\
\hline
\end{tabular}




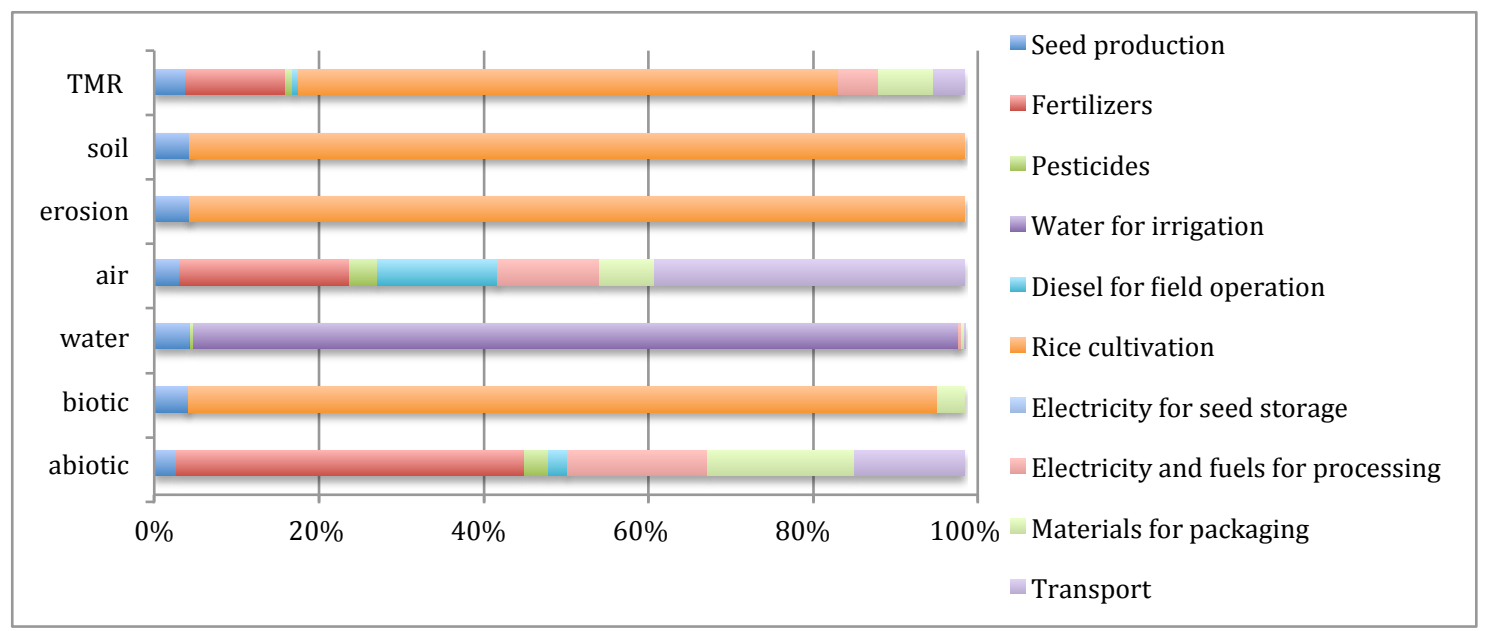

Fig. 3 Material intensity composition of milled conventional rice TMR

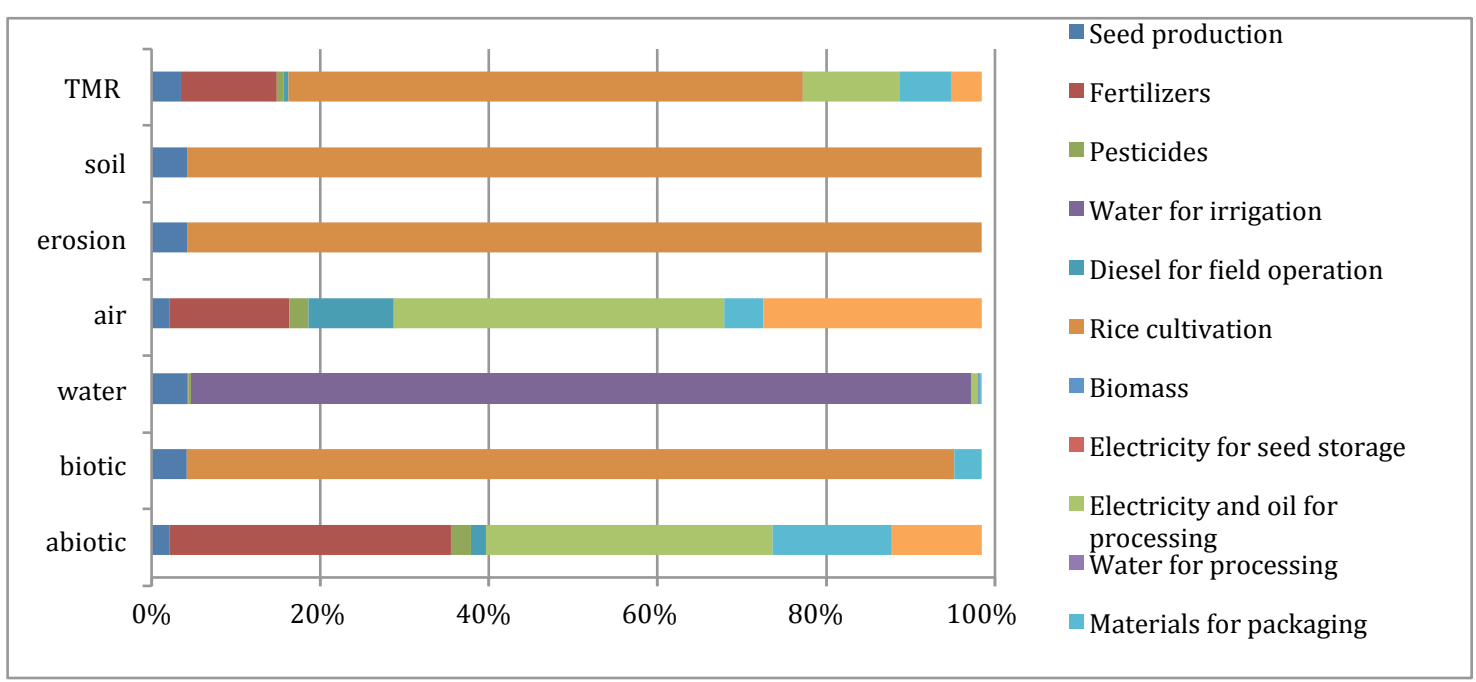

Fig. 4 Material intensity composition of parboiled conventional rice TMR

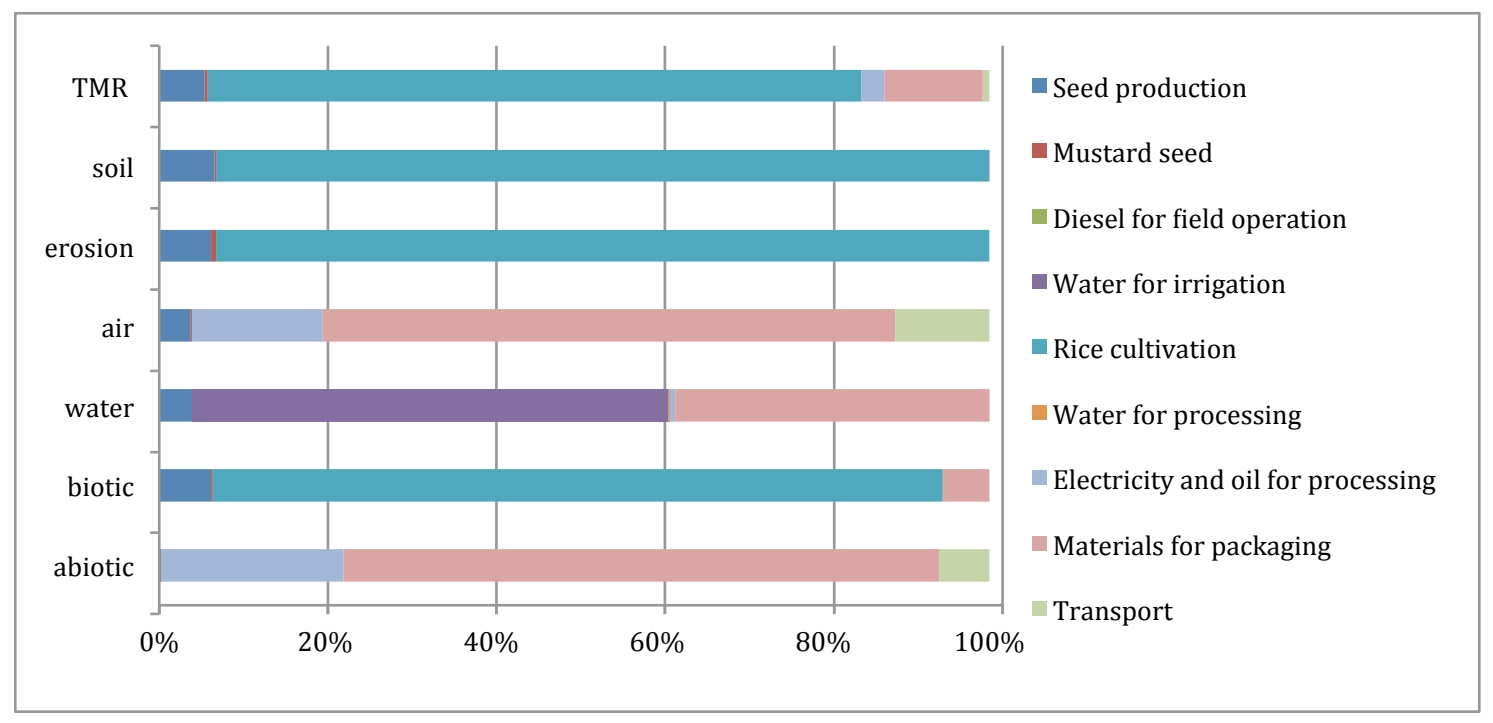

Fig. 5 Material intensity composition of organic milled rice 


\subsubsection{Results for oranges and citrus-based products}

Material intensity results are much more higher for $\mathrm{CJ}$, due to the minor yield of juice of a factor of five (35 kg of oranges for $1 \mathrm{~kg}$ of CJ, $7 \mathrm{~kg}$ of oranges for $1 \mathrm{~kg}$ of NJ). If we would consider products at the moment of consumption we should include the dilution of the concentrated juice, and these values will be more similar. Abiotic resource consumption is especially higher in CJ, due to the electricity and fuels for industrial processing (82\%) while fertilizers are responsible for about $50 \%$ of the abiotic resource consumption in NJ. Materials for packaging contribute overall in the air category ( $82 \%$ in $\mathrm{NJ}$ and $40 \%$ in $\mathrm{CJ}$ ), while water consumption depends most on irrigation. Considering oranges production fertilizers have a relevant influence on abiotic materials, accounting for $77 \%$ of the total. The impact of pesticides on the material input is negligible. Fertilizers, diesel for field operations and transport combine with almost equal parts to the total consumption of air.

Table 4. Material intensity of citrus-based products

\begin{tabular}{|l|c|c|c|c|c|c|c|}
\hline $\begin{array}{l}\text { Material } \\
\text { Intensity } \\
(\mathrm{kg} / \mathrm{kg})\end{array}$ & ABIOTIC & BIOTIC & EROSION & SOIL & WATER & AIR & TMR \\
\hline Oranges & 1.42 & 7.06 & 0.40 & 17 & 181 & 0.11 & 1.60 \\
\hline $\begin{array}{l}\text { Natural } \\
\text { orange juice }\end{array}$ & 2.17 & 7.06 & 121.9 & 2.82 & 1302 & 6.73 & 12.05 \\
\hline $\begin{array}{l}\text { Concentrated } \\
\text { orange juice }\end{array}$ & 35.56 & 35.27 & 609.5 & 14.1 & 6901 & 13.92 & 84.94 \\
\hline
\end{tabular}

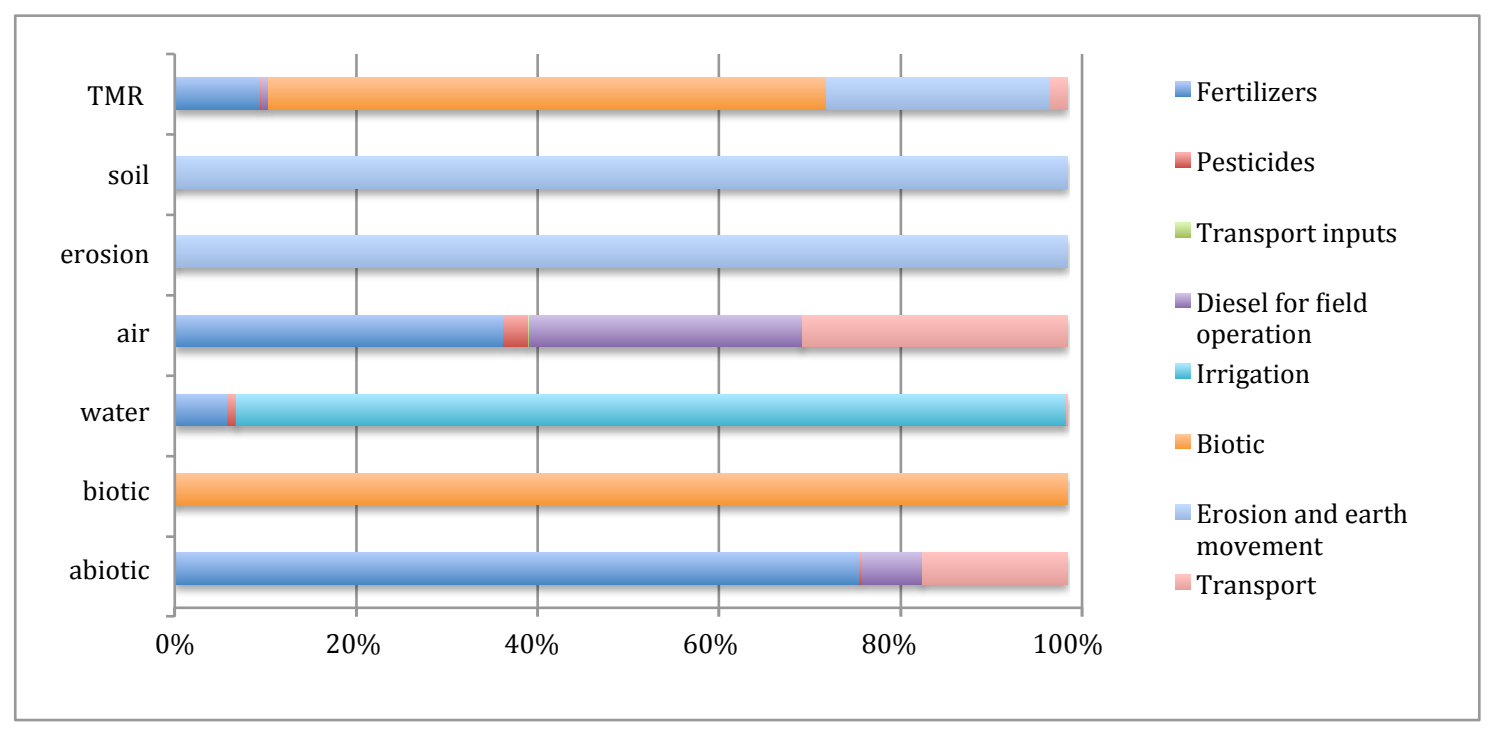

Fig. 6 Material intensity composition of oranges 


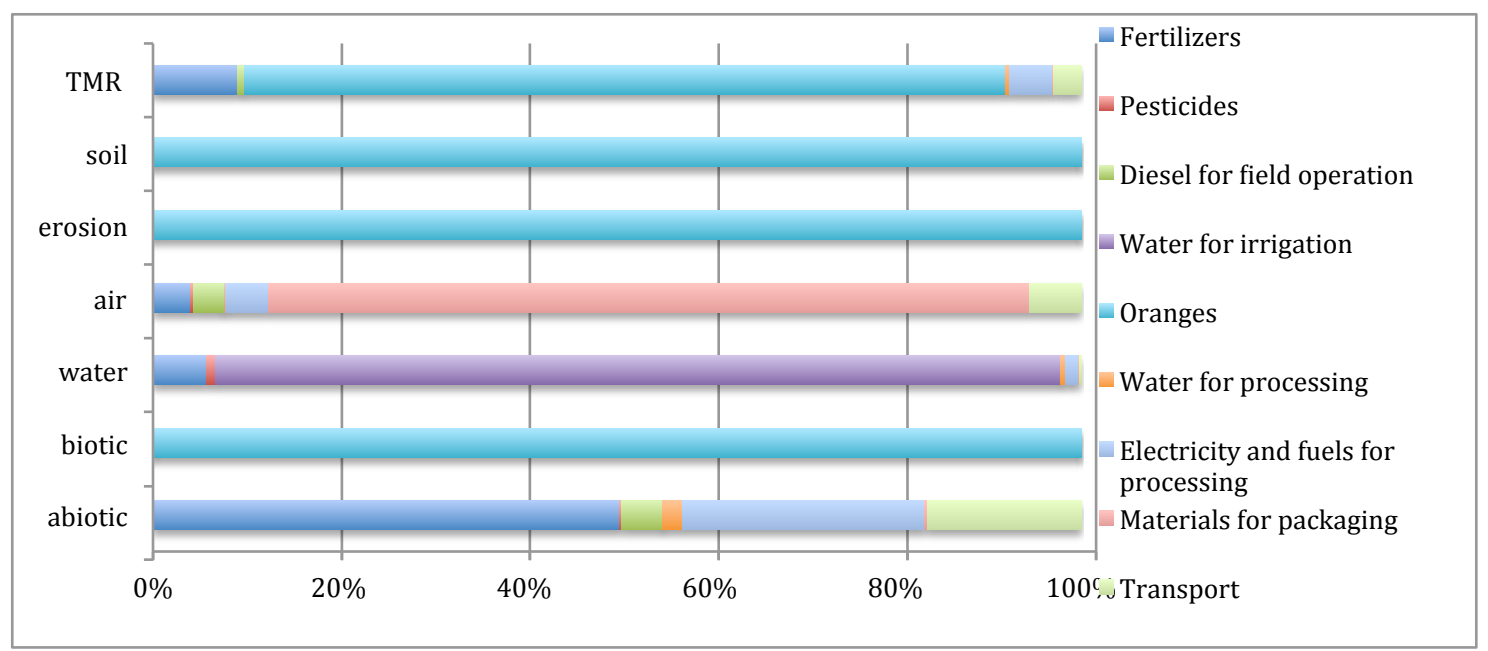

Fig. 7 Material intensity composition of natural orange juice

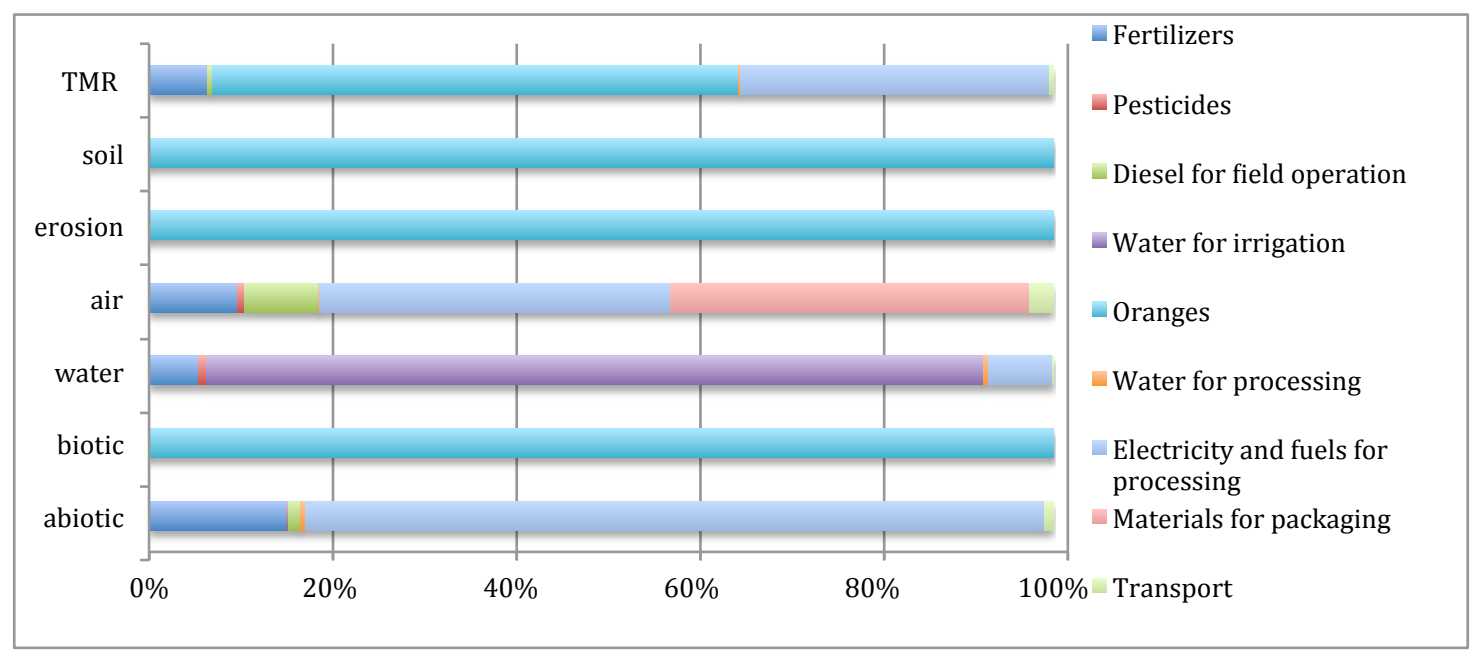

Fig 8 Material intensity composition of concentrated orange juice

\subsection{Resource intensity of European diets}

Fig. 9 and 10 show total annual consumption and TMR of the selected foodstuffs in the European countries. Results on the use of the three resources (materials, water and air) follow. We observe in fig. 9 that Germany, Austria and Italy have the highest value of AMI (see chapter 2.4 for indicators' equations), with 11.4, 11.3, $10.7 \mathrm{~kg}$ of material resources for producing $1 \mathrm{~kg}$ of food. Poland, with $8.4 \mathrm{~kg} / \mathrm{kg}$ has the lowest. Table 5 illustrates the share of different groups of foodstuffs (cereals and potatoes, fruits and vegetables, meat, fish and eggs, milk and dairy products, sugar, vegetable oils and fats) in the TMR for food. Countries in the table are graded according to the AMI values, from the less intensive up to the more intensive. Considering EU diet, the biggest share of material requirement is due to meat, fish and eggs consumption (36\%); milk and dairy products follow with $19 \%$. Not remarkable differences emerge between low and high-AMI countries in the composition of diets from this analysis. Considering the resource "water", fig. 12 and table 6 present results of intensity in water use (AWI) and composition of water requirements among the groups of food. Values for Italy and Portugal are 
considerably higher than the other countries (almost $250 \mathrm{~kg} / \mathrm{kg}$ vs. $92 \mathrm{~kg} / \mathrm{kg}$ of Poland). Looking at the table we can observe that water requirement are mostly due to cereals and potatoes in Portugal (61\%) and fruits and vegetables in Italy (42\%). The same categories have the biggest weight also in EU diet. Fig. 13 and table 7 illustrate the intensity of air (AAI) and the contribution of the different groups of food in the total air requirement (TAR), in each country. Italy is again the most intensive country, consuming $1.2 \mathrm{~kg}$ of air for each $\mathrm{kg}$ of food. Comparing with the values of EU, Italy presents higher share of fruit and vegetables (38\%). Sugar has a considerable impact in this category of resource in all the countries (32\% in EU).

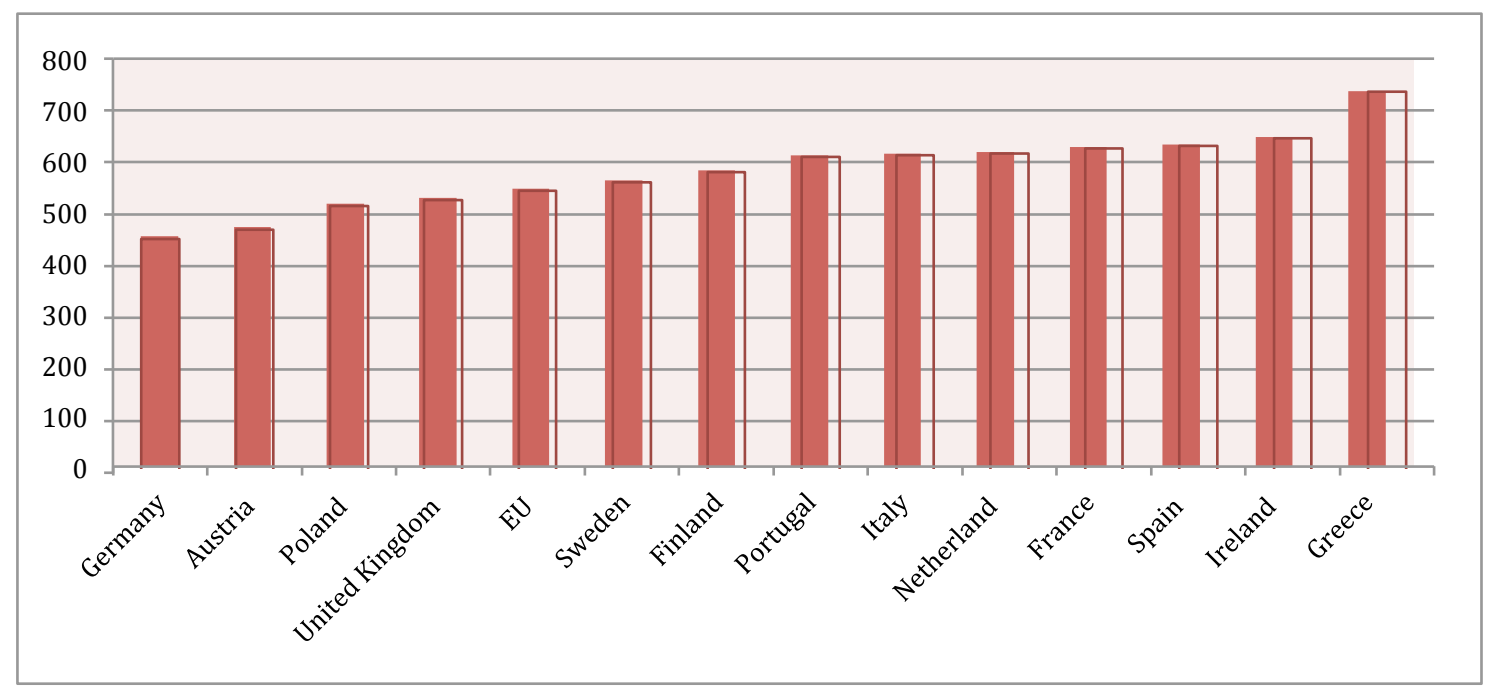

Fig.9 Total consumption of the selected foodstuffs in the 13 European countries and in EU (kg/capita/year)

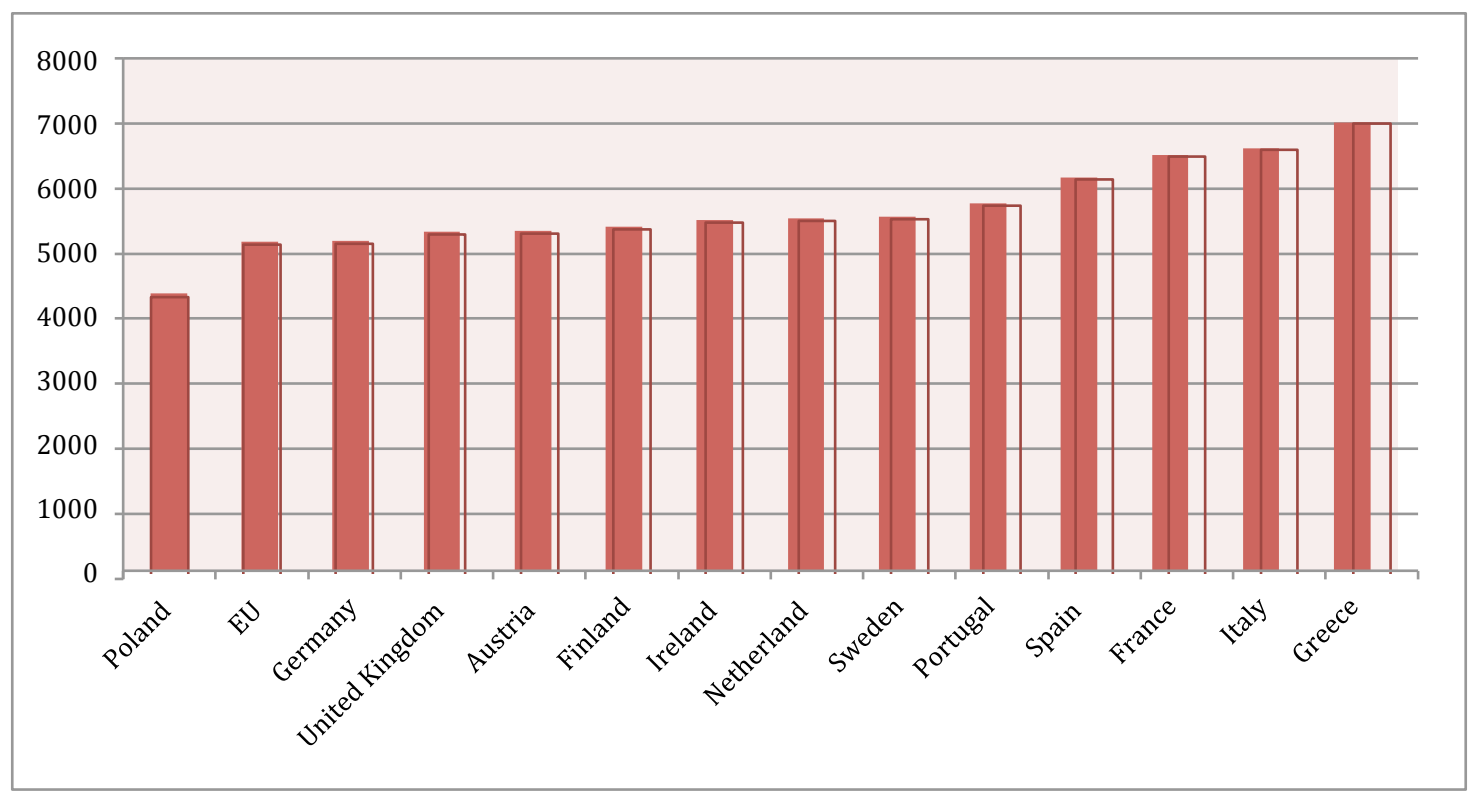

Fig. 10 Total Material Requirement for the selected foodstuffs' consumption in 13 European countries and in EU (kg/capita/year) 


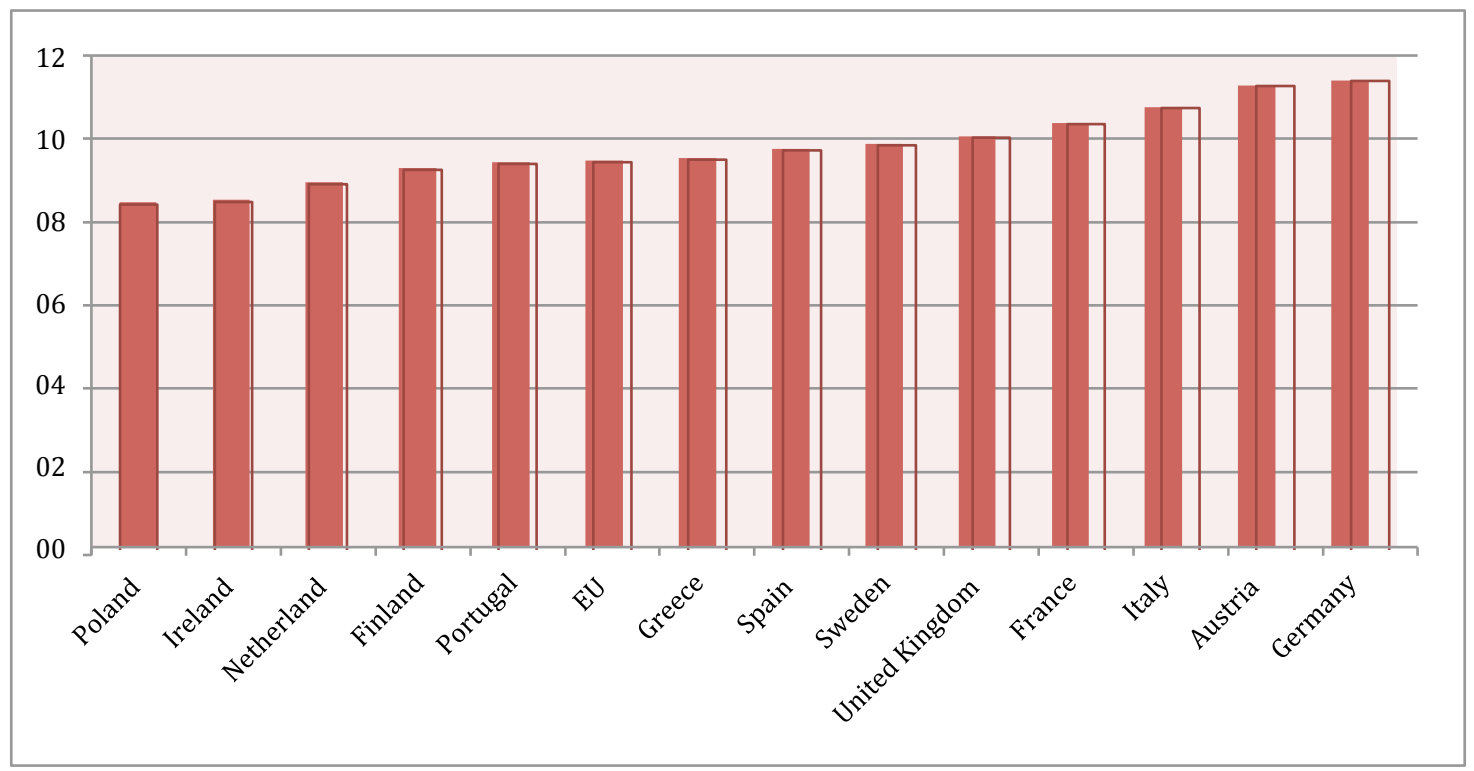

Fig. 11 Average Material Intensity of food in 13 European countries and EU $(\mathrm{kg} / \mathrm{kg})$ 
Table 5 Composition TMR of European diets among six groups of food (\%)

\begin{tabular}{|l|c|c|c|c|c|c|}
\hline AMI (\%) & $\begin{array}{c}\text { Cereals \& } \\
\text { Potatoes }\end{array}$ & $\begin{array}{c}\text { Fruits \& } \\
\text { Vegetables }\end{array}$ & $\begin{array}{c}\text { Meat, Fish } \\
\text { Eggs }\end{array}$ & $\begin{array}{c}\text { Milk \& Dairy } \\
\text { Products }\end{array}$ & Sugar & $\begin{array}{c}\text { Vegetable } \\
\text { Oils \& Fats }\end{array}$ \\
\hline Poland & 18.8 & 4.6 & 36.3 & 20.4 & 17.4 & 2.4 \\
\hline Ireland & 13.6 & 5.8 & 44.9 & 17.3 & 13.0 & 5.4 \\
\hline Netherland & 11.1 & 9.0 & 40.9 & 21.0 & 11.2 & 6.8 \\
\hline Finland & 9.2 & 6.6 & 37.8 & 28.2 & 16.3 & 1.8 \\
\hline Portugal & 16.0 & 5.2 & 48.0 & 11.8 & 11.8 & 7.3 \\
\hline EU & 15.5 & 7.8 & 36.1 & 18.8 & 15.1 & 6.7 \\
\hline Greece & 18.8 & 12.5 & 34.0 & 11.8 & 9.1 & 13.7 \\
\hline Sweden & 10.2 & 6.6 & 41.3 & 21.4 & 19.5 & 1.0 \\
\hline Spain & 12.1 & 7.5 & 48.2 & 10.9 & 10.6 & 10.7 \\
\hline UK & 14.6 & 3.5 & 45.9 & 17.0 & 10.0 & 9.1 \\
\hline France & 11.7 & 8.2 & 42.4 & 20.5 & 12.6 & 4.7 \\
\hline Italy & 15.6 & 11.7 & 36.7 & 12.9 & 14.8 & 8.3 \\
\hline Austria & 10.5 & 5.8 & 43.9 & 19.2 & 16.1 & 4.5 \\
\hline Germany & 11.4 & 5.0 & 38.2 & 22.3 & 16.2 & 6.9 \\
\hline
\end{tabular}

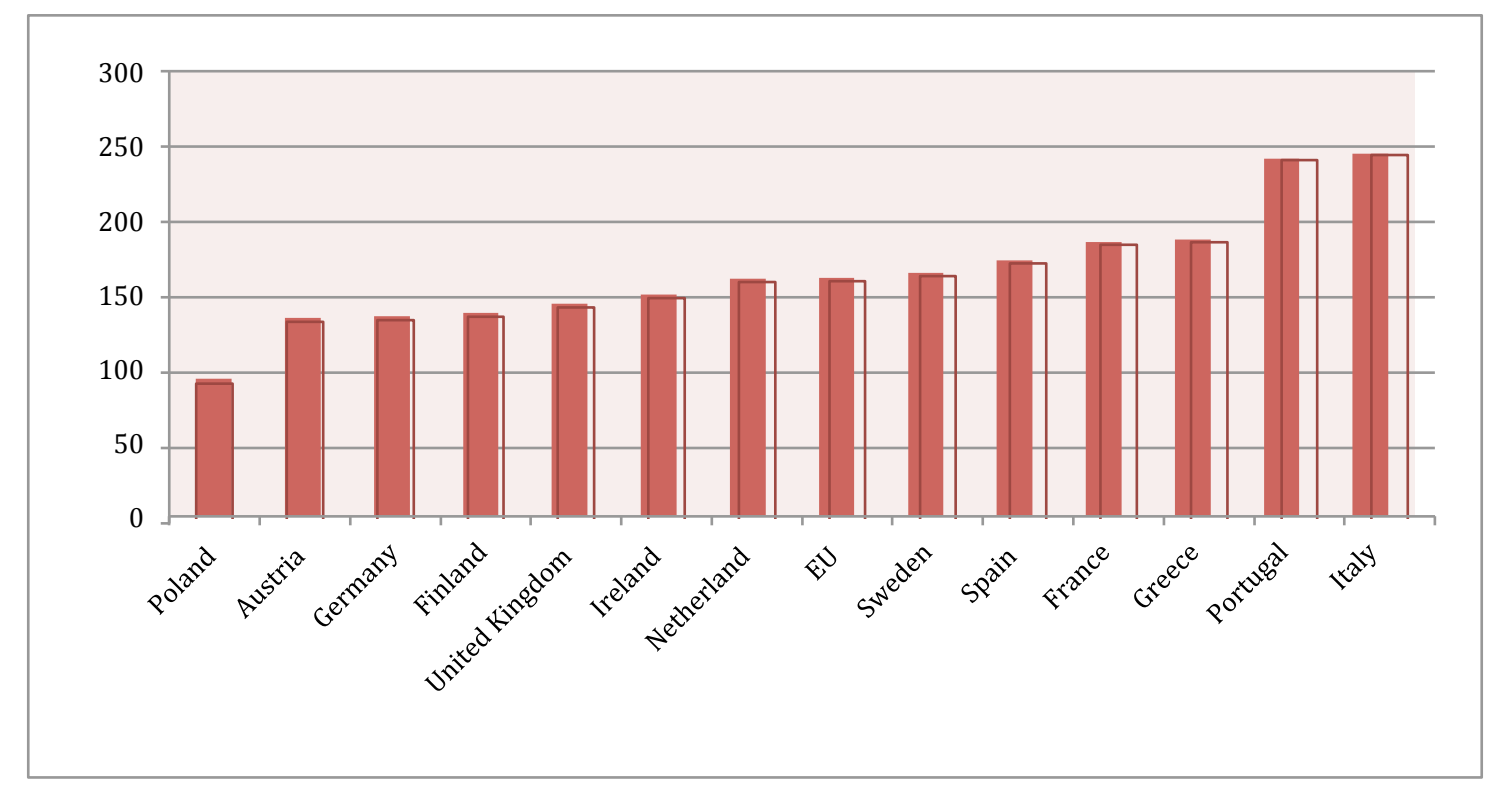

Fig. 12 Average Water Intensity of food in 13 European countries and EU (kg/kg) 
Table 6 Composition of water requirements of European diets among six groups of food (\%)

\begin{tabular}{|l|c|c|c|c|c|c|}
\hline AWI (\%) & $\begin{array}{c}\text { Cereals \& } \\
\text { Potatoes }\end{array}$ & $\begin{array}{c}\text { Fruits \& } \\
\text { Vegetables }\end{array}$ & $\begin{array}{c}\text { Meat, Fish } \\
\text { Eggs }\end{array}$ & $\begin{array}{c}\text { Milk \& Dairy } \\
\text { Products }\end{array}$ & Sugar & $\begin{array}{c}\text { Vegetable } \\
\text { Oils \& Fats }\end{array}$ \\
\hline Poland & 29.7 & 34.6 & 28.7 & 2.4 & 3.8 & 0.8 \\
\hline Austria & 28.9 & 32.1 & 32.2 & 2.1 & 3.3 & 1.4 \\
\hline Germany & 33.0 & 31.1 & 28.0 & 2.5 & 3.3 & 2.1 \\
\hline Finland & 30.2 & 35.3 & 29.0 & 2.5 & 2.6 & 0.4 \\
\hline UK & 41.1 & 18.0 & 35.4 & 1.5 & 1.7 & 2.3 \\
\hline Ireland & 42.6 & 27.3 & 26.0 & 1.3 & 1.8 & 1.1 \\
\hline Netherland & 25.6 & 46.6 & 23.4 & 1.5 & 1.5 & 1.4 \\
\hline EU & 36.0 & 36.5 & 22.6 & 1.4 & 2.1 & 1.4 \\
\hline Sweden & 38.1 & 30.5 & 26.7 & 1.7 & 2.8 & 0.2 \\
\hline Spain & 31.1 & 33.9 & 30.6 & 0.8 & 1.4 & 2.2 \\
\hline France & 30.8 & 39.3 & 25.7 & 1.5 & 1.7 & 0.9 \\
\hline Greece & 22.7 & 54.3 & 18.6 & 0.8 & 1.1 & 2.5 \\
\hline Portugal & 60.7 & 13.0 & 23.6 & 0.6 & 1.1 & 1.0 \\
\hline Italy & 37.5 & 42.3 & 16.7 & 0.7 & 1.6 & 1.3 \\
\hline
\end{tabular}

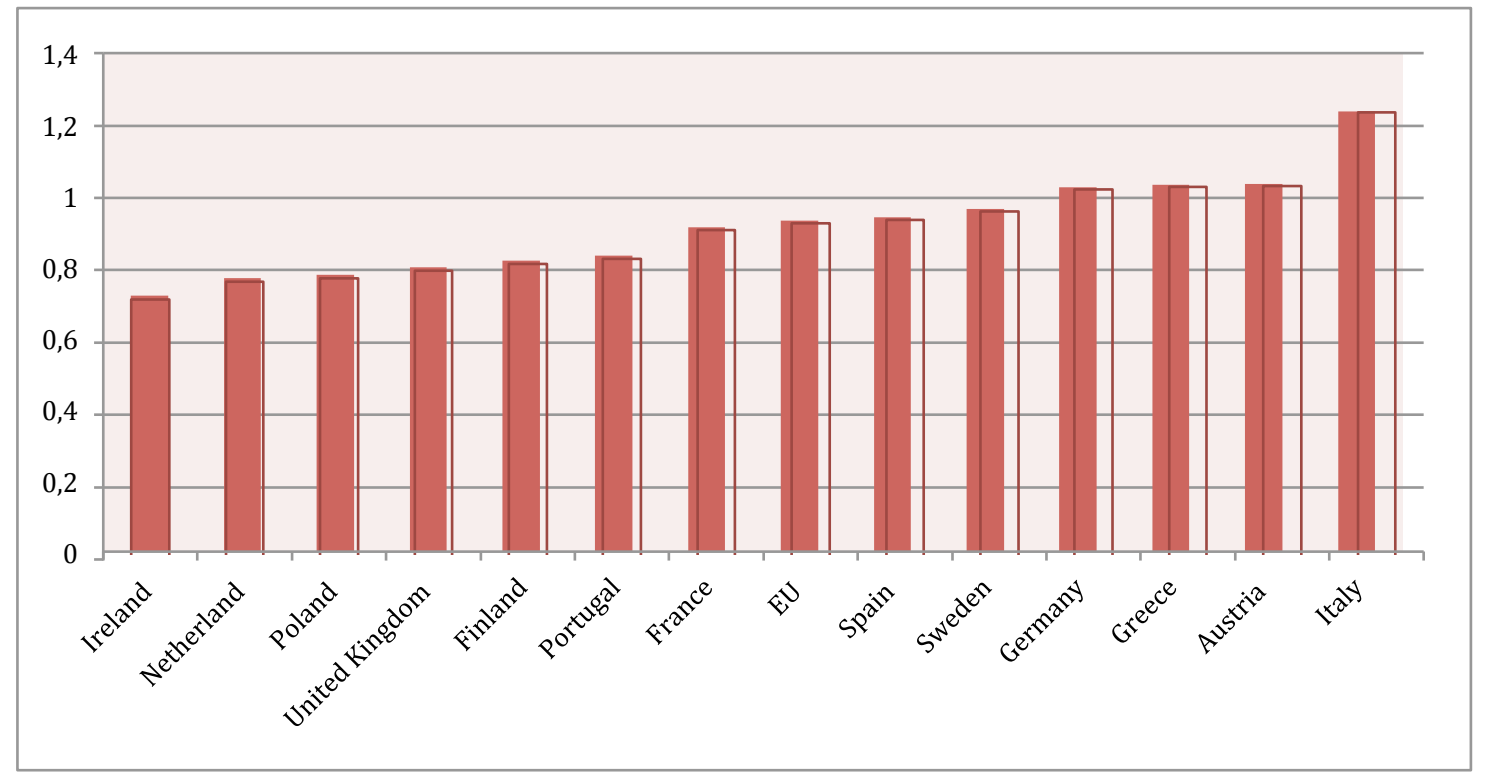

Fig. 13 Average Air Intensity of food in 13 European countries and EU (kg/kg) 
Table 7 Composition of air requirements of European diets among six groups of food (\%)

\begin{tabular}{|l|c|c|c|c|c|c|}
\hline AAI (\%) & $\begin{array}{c}\text { Cereals \& } \\
\text { Potatoes }\end{array}$ & $\begin{array}{c}\text { Fruits \& } \\
\text { Vegetables }\end{array}$ & $\begin{array}{c}\text { Meat, Fish } \\
\text { Eggs }\end{array}$ & $\begin{array}{c}\text { Milk \& } \\
\text { Dairy } \\
\text { Products }\end{array}$ & Sugar & $\begin{array}{c}\text { Vegetable } \\
\text { Oils \& Fats }\end{array}$ \\
\hline Ireland & 9.1 & 17.0 & 36.7 & 1.8 & 32.2 & 3.2 \\
\hline Netherland & 7.4 & 26.6 & 32.5 & 2.3 & 27.2 & 3.9 \\
\hline Poland & 11.3 & 18.1 & 27.6 & 2.0 & 39.7 & 1.3 \\
\hline UK & 10.8 & 15.3 & 39.9 & 1.9 & 26.5 & 5.6 \\
\hline Finland & 5.8 & 21.5 & 29.9 & 3.0 & 38.8 & 1.0 \\
\hline Portugal & 11.9 & 15.1 & 39.7 & 1.2 & 28.1 & 4.1 \\
\hline France & 8.5 & 23.8 & 32.8 & 2.3 & 30.0 & 2.6 \\
\hline EU & 9.7 & 26.5 & 26.3 & 1.8 & 32.3 & 3.4 \\
\hline Spain & 7.6 & 27.1 & 35.9 & 1.0 & 23.0 & 5.5 \\
\hline Sweden & 6.2 & 20.7 & 28.6 & 2.0 & 42.0 & 0.5 \\
\hline Germany & 7.5 & 19.6 & 28.7 & 2.4 & 38.0 & 3.8 \\
\hline Greece & 10.8 & 43.1 & 21.1 & 1.0 & 17.7 & 6.3 \\
\hline Austria & 6.9 & 19.8 & 32.0 & 2.0 & 36.9 & 2.5 \\
\hline Italy & 9.1 & 38.0 & 21.3 & 1.1 & 27.0 & 3.6 \\
\hline
\end{tabular}

A second step of analysis takes into account the whole hamper of foods, in order to evaluate the weight of each foodstuff in the total natural resource consumption for nutrition. For each foodstuff, we observed how much it weights in the food consumption (i.e. in the total amount of consumed food) and in the resources requirements.

The factor of difference between these two components is presented in table 8 . The figures are average values of all the countries. Factors are higher than 1 when the incidence on diet is smaller than incidence in the total resource consumption for that foodstuff. The higher is the factor, more resource intensive is the corresponding foodstuff. Butter, with 8.1, has the highest factor for TMR. This means that the share of TMR due to butter is 8 times higher than its share in total food consumption.

Cattle and sheep and goats are also highly resource intensive, with a factor of 5 and are then followed by sugar and vegetable oils and fats. Above we observed that "cereals" is the most impacting group for water. Factor's analysis indicates that rice is strongly affecting this value, with an average factor of 33.5. Tomatoes and meat (especially cattle and sheep) are also important groups contributing to water consumption, with a factor of 5.5 and 3.1.

Regarding the air category sugar is confirmed to have a severe impact. Its incidence in resource use is 5.3 times the incidence in food consumption. Tomatoes and meat (meat and sheep and goat) are also quite intensive, with factors of 4.5 and 3.2 , respectively. 
Table 8 Average factor of difference between food consumption share and resource use share

\begin{tabular}{|l|c|c|c|}
\hline & TMR & Water & Air \\
\hline Wheat & 0.6 & 0.3 & 0.4 \\
\hline Rice & 0.9 & 33.5 & 1.1 \\
\hline Potatoes & 0.1 & 0.0 & 0.0 \\
\hline Vegetable oils \& fats & 2.0 & 0.5 & 1.1 \\
\hline Sugar & 2.3 & 0.4 & 5.3 \\
\hline Apples & 0.2 & 0.0 & 0.0 \\
\hline Oranges & 0.2 & 1.3 & 0.1 \\
\hline Pears & 0.2 & 0.0 & 0.0 \\
\hline Fresh tomatoes & 0.9 & 5.5 & 4.5 \\
\hline Cattle & 5.0 & 3.1 & 3.2 \\
\hline Poultry & 1.9 & 1.6 & 1.8 \\
\hline Pigs & 1.6 & 0.4 & 1.1 \\
\hline Sheeps \& goats & 5.0 & 3.1 & 3.2 \\
\hline Fish \& seefood & 0.8 & 1.9 & 0.9 \\
\hline Drinking milk & 0.4 & 0.0 & 0.0 \\
\hline Butter & 8.1 & 0.7 & 0.9 \\
\hline Cheese & 2.0 & 0.2 & 0.2 \\
\hline Eggs & 0.4 & 0.2 & 0.3 \\
\hline
\end{tabular}

\section{Interpretation of results}

The analysis of three food chains showed how different elements and phases in the production are having an environmental impact. We observed the organic rice farming impact being almost similar to the conventional one, due to the use of a bigger area of land for gaining the same unit of food. A major use of the soil implies consequently a higher value of erosion. The consumption of biotic resources, bigger then in conventional rice, is also due to the use of mustard seed, the cotton bag for packaging and the major amount of seeds for hectare that is required (200 $\mathrm{kg} / \mathrm{ha}$ vs. $120 \mathrm{~kg} / \mathrm{ha}$ of conventional one).

The saving of abiotic raw materials is instead relevant once chemical products for agriculture are avoided and transport distances are reduced, like in the organic farm.

In general, a minimization of external inputs employment contributes to reducing production costs and can improve the farm profitability. A specific MIPS analysis on a production system allows the comparison of different strategies of farm management and the evaluation of the most efficient in terms of input/output rates. Instead, the results on rice disclose that a major yield does not imply a higher productivity when this gain is obtained with more than proportional inputs. The better performance of organic rice in the category of abiotic materials that encompasses all the external and purchasable inputs like agro-chemicals, electricity, fuels, etc. as well as the hidden material flows behind these) suggests that the farm profitability can be improved through the strategy of minimizing the 
inputs instead of the most common "productivist" scheme of yield maximization.

Although toxicity is not especially evaluated in the MIPS concept, the impact of pesticides and other chemicals on the results is visible. However, with the resources of this study it was not possible to perform a detailed material intensity assessment of the use of pesticides that are applied in smaller and smaller doses thanks to technological progress.

The calculation of natural resource consumption due to nutrition in European countries used the same material intensities of foodstuffs, which came from three different areas of production: Italy, Germany and Finland. Thus, the only variable was the amount of different foodstuffs that are consumed in each country. For this reason an analysis of diets' compositions allow gleaning which elements in food habits are more responsible for a high intensity in resources use.

Meat and animal based products demonstrated requirement for a large amount of material resources, confirming the evidence from other studies using different assessment methods (e.g., greenhouse gas emissions in Kramer et al., 1999).

The high water consumption of rice has also been also proven. High values for fruits and vegetable are probably affected by using MIPS values from Finnish productions. Calculation could be repeated once data from a more suitable area of production is available.

MIPS was also applied in a research on food consumption in Finnish households in Kotakorpi et al. (2008). In this project data on consumption are from direct interviews with the households. Using the Finnish data basis on material intensity of foodstuffs the TMR of each household was calculated (Fig. 14).

In this case, we observe a higher variability of results than when comparing the countries' diets. Statistics do not provide the same insight into the impact of different lifestyles and consumption patterns as detailed as micro level studies. Nevertheless, statistics can show differences in the impact of average diets of different countries even without the need for in-depth study of the specific households.

Concerning the components of TMR in Finnish households, the biggest share comes from dairy products and meat consumption. 


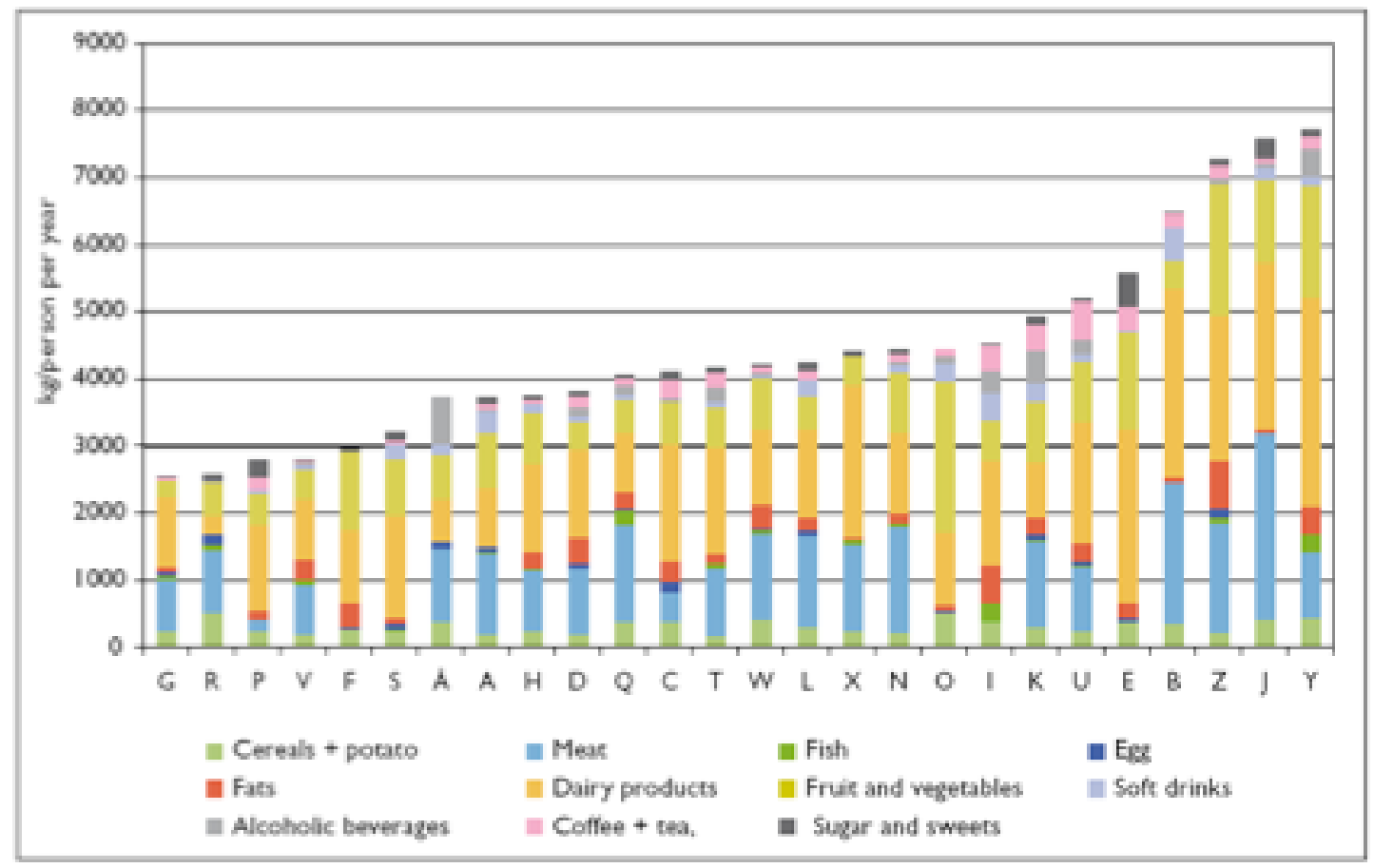

Fig. 14 Contribution of the sub-components to the TMR of foodstuffs for 27 Finnish households (from Kauppinen et al. 2008)

\section{Conclusions}

The actual trend of growing population and economic development in some countries represents new challenges for the agricultural sector in terms of food supply capacity and natural resource management. Food systems are asked be productive, but at the same time to preserve the available natural resources. Sustainability is becoming an urgent need and governments, international institutions and local administrations are approaching new initiatives to promote sustainability in food production and consumption.

Concerning the food supply, MIPS results suggest that policy should foster the ecoefficiency of agricultural processes and turn them towards a lower use of external inputs. It would provide a double benefit. On the one hand, the environmental protection is improved; while on the other hand, it contributes to reducing the dependence on supplier inputs and cutting the production costs. At the same time, results showed that food transportation contributes substantially to the air and abiotic materials' consumption. Sustaining and propelling local food systems, can produce considerable advantages for the producers, the consumers, and a sustainable regional development.

From the analysis of European countries' diets emerged that cattle, sugar and butter are the most resource intensive foodstuffs (fruits and vegetables are very demanding in water and air, but the data used refers to the Finnish production, and it stands to reason that these would change significantly considering crops on 
a more favorable climatic condition).

These outcomes hint that a reciprocal relation could exist between the environmental performance of food production and its healthiness. Many studies have pointed to the negative effects of high meat, sugar and fat consumption and our results confirmed that these products embody huge amount of natural resources. Thus, acting on eco-efficiency and natural resource saving could enable the achievement of positive effects on the environment and on health at the same time. Obesity, diabetes and many other diseases caused by a bad nutrition have enormous costs in terms of public expenditure. The chemicals used in agriculture are also dangerous for the health as well as more processed and treated foodstuffs containing higher amounts of additives, preservatives and other harmful substances. An agricultural policy focused on the reduction of inputs

and on the production of natural and healthy food would contribute to reducing the expenditures for the public health, and preserving the ecosystems. Contemporaneously, spreading a basic knowledge on sustainability and raising public awareness of the benefit of a healthy nutrition would contribute to creating and reinforcing a demand for an organic and low-impact agriculture.

Sustainability requires a reduction of material throughputs in the economies and the optimization of resources productivity (Risku-Norja and Mäenpää, 2007). For this purpose physical inputs have to be evaluated in an unambiguous way and for the whole food chain.

At the same time, the promotion of sustainability needs suitable and readily communicable indicators for guiding consumers and producers' choices, as well as appropriate tools for supporting decision-making.

MIPS has been used for an assessment of the natural resource consumption in agro-food systems. The methodology allowed encompassing different aspects of nutrition's environmental burden, providing a raw estimation of the use of nature due to this activity, both from the supply and demand side.

Concerning the production of food, we observed that the most important phases affecting the sustainability of the supply chain are the agricultural phase in rice and wheat and the processing phase one in orange juices. In the latter case, an ecoefficiency strategy should basically focus on the energy provisions. Fuels and electricity efficiency should be improved and the use of low input energy sources (see e.g. Rohn et al., 2010) could be evaluated in order to reduce the impact. Improving sustainability in agriculture can be obtained through a decreasing of pesticide use in the case of wheat and improving the efficiency in water use in rice cultivation.

Sustainability in food consumption has been evaluated through the calculation of a set of indicators based on material, water and air intensities. The Italian diet was shown to be the least sustainable for the three categories of resources. On the contrary, the Polish diet is the most sustainable.

Results confirmed the high impact of animal products, especially for the material resources. Between them, cattle provide the most resource-intensive meat. Sheep 
and goats present the same results because we assumed MIPS figures to be equal to the ones of cattle. Butter has also an important impact on material resources while rice is heavily affecting water requirements. Fruits and vegetables have high water and air requirements and tomatoes are the most resource-intensive crop in this group. Crop irrigation and greenhouse infrastructures can explain this result.

Further research could outline how much results would vary when applying more country-specific data, e.g. when considering open field tomato crops in Mediterranean areas instead of greenhouse cultivation in Finland. Moreover the material intensity evaluation should be extended to many other products in order to achieve a broader data basis for the evaluation of natural resource consumption.

On the basis of this first attempt of evaluating sustainability of food production and consumption many developments are possible. Land use could be integrated in the analysis, including the occupation of soil in the natural resource consumption due to nutrition.

In a macroeconomic perspective, the use of resources in agriculture could also be related with economic indicators, in order to trace the trend of the sector in terms of sustainability over time. From a microeconomic point of view, the assessment of material intensity along the supply chain can help implementing eco-efficiency strategies. Further research at this level could investigate the relation between a low application of external inputs in agriculture (using a material intensity approach) and the profitability of these farms, in comparison with others adopting more intensive farming techniques.

\section{References}

Baedeker, C., C. Kaiser, S. Kolberg, C. Liedtke and H. Wallbaum (2008) Resource intensity in global food chains: examples of hot spot analysis. Presentation held at IGLS International Conference on System Dynamics and Innovation in Food Networks, Innsbruck, Austria, 1822 Feb. 2008.

Beccali, M., M. Cellura, M. Iudicello, M. Mistretta (2009) Resource Consumption and Environmental Impacts of the Agrofood Sector: Life Cycle Assessment of Italian CitrusBased Products Environmental Management 43: 707-724.

Bevilacqua, M., M. Braglia M, G. Carmignani, F.A. Zammori (2007) Life Cycle Assessment of pasta production in Italy Journal of Food Quality 30: 932-952.

Bevilacqua, M., P. Buttol, F. Cecchini, L. De Pietri, P. Neri, L.F. Ruini (2001) Analisi del ciclo di vita di due tipi di pasta della ditta Barilla. ENEA Report, Bologna.

Blengini G. A., Busto, M. (2008) The life cycle of rice: LCA of alternative agri-food chain management systems in Vercelli (Italy) Journal of Environmental Management 90:15121522.

Bringezu S., Y. Moriguchi (2002) Material flow analysis. In Handbook of Industrial Ecology, R.V. Ayres, L. W. Ayres, Edward Elger Publishing.

Bringezu S., H. Schütz (2001) Total material requirement of the European Union. Technical 
Report E. E. Agency, Copenhagen European Environment Agency 35.

Burger E., S. Giljum., C. Manstein, F. Hinterberger (2009) Comprehensive ecological indicators for products: three case studies apllying MIPS and ecological footprint. Presentation held at 8th International Conference of the European Society for Ecological Economics, Ljubljana, Slovenia, 29th June - 2nd July.

De Fraiture, C, D. Molden, U. Amarasinghe, I. Makin (2001) PODIUM, projecting water supply and demand for food production in 2025 International Water Institute 26(1112):869-876.

Della Corte, C., F. Cecchini, F. Franchini, G. Scherillo, P. Neri, P. Naddeo (2003) Analisi del ciclo di vita di $1 \mathrm{~kg}$ di pasta della ditta "Antonio Amato". ENEA Report, Bologna.

EEA (2001) Total material requirement of the European Union, Technical Report No 55.

EUROSTAT (2008) Food: from farm to fork statistics. Pocketbooks. Luxemburg.

FAO, 2010. Forest insects as food: humans bite back. In: Proceedings of a workshop on Asia-Pacific resources and their potential for development, Chiang Mai, Thailand, 19-21 February 2008.

Hahlbrock, K. (2009) Feeding the Planet: Environmental Protection through Sustainability. Haus Publishing, London.

Hinterberger F., E. K. Seifert (1997) Reducing Material Throughput: A Contribution to the Measurement of Dematerialization and Sustainable Human Development. In Environment, Technology and Economic Growth - The Challenge to Sustainable Development. Tylecote A., van der Straaten J., Cheltenham, UK - Northhampton, MA, USA Edward Elgar.

ISTAT (2003) 1980-1998 Material-Input-Based Indicators Time Series and 1997 Material Balance of the Italian Economy. Rome.

Kauppinen, T. S. Lähteenoja, M. Lettenmeier (2008) Data Envelopment Analysis as a Tool for Sustainable Foodstuff Consumption. Presentation held at 2nd Conference of the Sustainable Consumption Research Exchange (SCORE!) Network, Brussels, Belgium, 10-11 March 2008.

Kotakorpi, E., S. Lähteenoja, M. Lettenmeier (2008) Household MIPS - Natural resource consumption of Finnish households and its reduction. Helsinky.

Kramer, K. J., H. C. Moll, S. Nonhebel, H. C. Wilting (1999) Greenhouse gas emissions related to Dutch food consumption Energy Policy 27(4): 203-216.

Lettenmeier M., Rohn H., Liedtke C., Schmidt-Bleek (2009) Resource productivity in 7 steps. How to develop eco-innovative products and services. Wuppertal Spezial (Draft).

Lettenmeier, M., A. Maijala (2006) Eco-efficiency Management of Municipal Services: Water Supply, Delivery and Wastewater Treatment article draft.

Lettenmeier M., V. Salo, (2008) Natural resource consumption of different waste policy options in the Helsinki metropolitan area, Presentation held at ConAccount 2008 Urban metabolism: measuring the ecological city, Pregue Czech Republic, 11- 12 September 2008.

Mandelli, S., P. Neri., L. Bruni, L. Stanca, F. Cecchini, F. Franchini (2005) LCA - Fattori di caratterizzazione nella categoria human health. Applicazione allo studio della produzione di riso. Enea Report, Bologna.

Pimentel D., M. H., Pimentel (2008). Food, energy and society. New York, CRC Press. 
Risku-Norja H., I., Mäenpää (2007) MFA model to assess economic and environmental consequences of food production and consumption Ecological Economics (60: 700-711).

Ritthoff, M., C. Kaiser and H. Rohn (2009) Wie viel Natur kostet unsere Nahrung? Ein Beitrag zur Materialintensität ausgewählter Produkte aus Landwirtschaft und Ernährung. NRW, Wuppertal Papers Wuppertal Institute.

Ritthoff, M., H. Rohn, C. Liedtke, T. Merten (2002) Calculating MIPS - Resource productivity of products and services. Wuppertal Special 27e, Wuppertal Institute. Available at at www.mips-online.info

Rohn, H., Wiesen, K., Lettenmeier, M., Pastewski, N., (2010) Quantitative benefits of sustainable innovation: resource efficiency potentials of technologies, products and strategies. In: Paper Presented at Sustainable Innovation 2010, Creating Breakthroughs: Green growth, Eco-innovation, Entrepreneurship and Jobs - 15th International Conference 'Towards Sustainable Product Design', Rotterdam, The Netherlands, 8th-9th November

Schmidt-Bleek, F. (2008) The Earth - Natural Resources and Human Intervention, Haus publishing, London.

Schmidt-Bleek, F., (1993). The Fossil Makers, English translation of "Wieviel Umwelt braucht der Mensch? MIPS - Das Maß für ökologisches Wirtschaften".Available from: http://factor10-institute.org/publications.html.

Spangenberg, J.H., F. Hinterberger, S. Moll, H. Schütz (1999) Material Flow Analysis, TMR and mips-Concept: A Contribution to the Development of Indicators for Measuring Changes in Consumption and Production Patterns International Journal of Sustainable Development 2(4): 491-505.

United Nations, et al. (2003), Integrated Environmental and Economic Accounting 2003Handbook on national accounting, United Nations, European Commission, International Monetary Fund, OECD, World Bank. 